\title{
Disease suppression in winter wheat from novel symbiosis with forest fungi
}

Mary Ridout ${ }^{\mathrm{a},}$, George Newcombe ${ }^{\mathrm{a}}$

${ }^{\mathrm{a}}$ Department of Forest, Rangelands and Fire Sciences, University of Idaho, Moscow ID 83844-1133, USA.

*Corresponding author. Tel.: +1 5093220485 Fax: 2088856564

Email addresses: mridout@uidaho.edu (M. Ridout), georgen@uidaho.edu (G. Newcombe).

(C) 2015. This manuscript version is made available under the Elsevier user license http://www.elsevier.com/open-access/userlicense/1.0/ 


\begin{abstract}
In the Pacific Northwest, USA, pathogenic Fusarium spp. are common in agricultural soils but rare in forest soils. We hypothesized that regional forest soils possess indigenous, Fusarium-suppressive microbes which may enter into novel associations with introduced crop plants, potentially contributing to suppressive soils. To test this hypothesis, we inoculated winter wheat with regional forest litter microbial communities and rhizosphere fungi and challenged plants with pathogenic Fusarium culmorum from regional agricultural fields. We also challenged plants with drought and low-temperature stress, which may augment disease severity. A forest litter microbiome improved survival of Fusarium-infected wheat three-fold and increased growth by $67 \%$. Seedlings inoculated with individual forest fungi developed larger root systems during vernalization. Penicillium sp. doubled yield of Fusarium-infected winter wheat exposed to drought conditions. Indigenous microbes from native plant communities of the interior Northwest mitigate abiotic stresses and may contribute to suppression of a soil-borne wheat disease via novel symbioses.
\end{abstract}

Key words: Suppressive soils; forest microbes; pine litter microbiome; winter wheat; Fusarium culmorum; Penicillium; DSE

\title{
Introduction
}

Disease-suppressive soils have been defined as soils in which the incidence, severity, or virulence of a soil-borne pathogen is reduced compared to adjacent soils or is lower than expected for environmental or soil conditions (Weller et al., 2002). Disease-suppressive soils have long been of interest to plant pathologists (Burke, 1954; Kinkel et al., 2011; Shipton et al., 1973), and it is now widely recognized that members of soil microbial communities are the primary mediators of disease suppression (Kinkel et al., 2011; Weller et al., 2002).

Symbioses occur when two or more highly differing organisms form a close physical association by which one or more of the organisms benefits (de Bary, 1879). Novel symbioses between indigenous microbes and introduced plants can be mutualistic (Baynes et al., 2012; Richardson et al., 2000), but they have never been shown 
to contribute to disease suppression in soils. Suppression of plant diseases in soils has been attributed to activities of both single microbes and microbial communities (Kim et al., 1997; Mazzola, 1999), but much of the literature has focused on disease suppression by bacterial communities (Kim et al., 1997; Mazzola, 1999) or single isolates of bacterial and fungal genera previously associated with biocontrol of pathogens, including Pseudomonas (Kloepper et al., 1980: Weller and Cook, 1983), non-pathogenic Fusarium (Larkin et al., 1996), and Trichoderma (Liu and Baker, 1980). Moreover, most active suppressors have been reported from agricultural fields (Liu and Baker, 1980; Sher and Baker, 1980; Weller, 1983) where crop species, tillage practices, and cropping history play a significant role in the formation and dissolution of disease-suppressive microbial communities (Cook, 1981; Mazzola, 1999; Peters et al., 2003). Disease-suppressive soils have been well documented across dryland agricultural fields in the arid interior Pacific Northwest (PNW), USA (Shipton et al., 1973; Weller and Cook, 1983; Weller et al., 2002), with their mechanism most frequently ascribed to Pseudomonas bacteria (Weller, 1983; Raaijmakers, 1997; Weller et al., 2002). More rare are studies examining the suppressive potential of microbes from undisturbed soils (Smith, 1967; Schisler and Linderman, 1984).

In the arid intermountain region of the PNW, most agricultural fields were developed from shrubsteppe grassland prairie, pine woodlands, and the margins of dry intermountain forests (Black et al., 1998). Conversion of natural communities, followed by continual annual cropping, has led to the build-up of undesirable pathogens (Cook, 1980) and a loss of indigenous diversity in the soil microbiome (Smiley and Patterson, 1996; Fierer et al., 2013). In these converted fields, the dominant dryland crop of this region is wheat (Triticum aestivum), a domesticate of western Asian origin. In dryland wheat production, Fusarium culmorum is a significant root and crown rot pathogen (Cook, 2007). Fusarium culmorum severity may be mitigated with rotational cropping, but dryland farming in the PNW, where wheat is often grown in short, 2-year rotations to maintain soil moisture, limits rotational effectiveness against outbreaks (Cook, 1980: Paulitz, 2006). Moreover, increased use of conservation tillage to reduce wind and water erosion leaves pathogen-carrying residues on the soil surface, increasing the severity and incidence of the disease (Cook, 2007). Not only are Fusarium crown and root rots costly in terms of plant survival and yield, but they are often most severe during periods of drought when plants are already stressed (Cook and Papendick, 1972; Papendick and Cook, 1974). Even among these intensively cultivated soils, Fusariumsuppressive soils have been documented, as they have throughout North America and around the world (Burke, 1954; Alabouvette, 1979; Lin and Cook, 1979; Sher and Baker, 1980; Larkin et al., 1996; Weller et al., 2002). 
Microbial communities of forest litter and forest soils from western North America have been known to suppress pathogenicity and reduce the fecundity of Fusarium spp. (Schisler and Linderman, 1984), and may eventually reduce the incidence of the pathogen in the soil. For example, Smith (1967) found forest soils gradually reduced presence and viability of pathogenic Fusarium oxysporum in the root zone of infected Pinus lambertiana. In pilot surveys of coarse-fine roots of 17 native shrubs and trees in undisturbed forests and shrublands across the arid intermountain PNW, we found only eight isolates of Fusarium out of nearly 7000 fungal isolates (Ridout and Newcombe, unpublished data). Interestingly, $65 \%$ of all culturable root-associated microbes (both fungal and bacterial) isolated in these surveys belonged to fungal genera associated with the ability to survive xeric conditions and extreme temperatures: Penicillium and Phialocephala (Bollen and Wright, 1961; Pitt, 1973; Trowbridge and Jumpponen, 2004; Frisvad et al., 2006; Vyas et al., 2007; Houbraken et al., 2012; Knapp et al., 2012). By mediating tolerance to abiotic stresses in plant hosts (Ait Barka et al., 2006; Baynes et al., 2012; Hubbard et al., 2014), plantassociated microbiomes may also reduce the severity of soil-borne pathogens, such as F. culmorum, that are most damaging under stressful conditions (Cook, 1973; Papendick and Cook, 1974; Gaudet and Chen, 1987).

Novel symbioses that form between indigenous microbes and exotic or non-indigenous plants can be highly beneficial to the host, forming the so-called "enhanced mutualisms" (Richardson et al., 2000; Baynes et al., 2012). Populating soils that have never been cultivated for field crop production (Kershaw et al., 1998; Turner and Kuhlmann, 2014), many of the microbes found in the rhizopheres of forests and woodlands of the arid interior PNW may well represent part of indigenous microbial communities once found in soils where dryland wheat fields are now cultivated. Just as indigenous microbes form enhanced mutualisms with invasive, exotic winter annuals (Baynes et al., 2012), microbes from these indigenous soil and root communities may form beneficial, novel symbioses with wheat. Given the relative absence of Fusarium among root-associated microbes of forests and woodlands of the arid interior PNW, we hypothesized that fungi indigenous to these forest microbial communities would form novel symbioses capable of suppressing the severity of Fusarium crown rot if inoculated into wheat under conditions favoring disease due to Fusarium culmorum.

To test this hypothesis, we conducted a series of experiments with wheat, testing the Fusarium-suppressive effects of a litter microbial community from a PNW Ponderosa pine (Pinus ponderosa) woodland and individual fungi including the litter fungus Morchella snyderi and species of Penicillium and Phialocephala from the root 
microbiome of Douglas fir (Pseudotsuga menziesii var. glauca). Penicillium and Phialocephala represented the most common genera found in microbial communities indigenous to these arid forests and woodlands, and $M$. snyderi represented a genus previously associated with increased heat tolerance, growth, and fecundity in an exotic winter annual (Baynes et al., 2012). Since drought-stress augments severity of $F$. culmorum infection, a moisture deficit was added as an abiotic stress in the experiment testing the ability of these single fungi to mediate tolerance to drought stress and suppress $F$. culmorum in winter wheat. We also tested individual microbes for their ability to mediate tolerance of low-temperature stress associated with vernalization-a stress which may reduce plant fitness and ability to resist other abiotic and biotic stresses.

\section{Materials and Methods}

Fusarium culmorum, drought, and wheat - effects of single species of fungi

To determine whether xerophilic and drought-adapted fungi could promote drought tolerance in winter wheat either by directly facilitating drought resistance or by suppressing crown rot pathogens, we designed a three-factor factorial experiment with five fungal treatments, two pathogen treatments, and two levels of moisture. Seeds of a single line of hard red winter wheat (University of Idaho line 306 UI-SRG) were sown in $2 \mathrm{~cm}^{3} 200$-cell trays nested in seed flats. Seedlings were sprouted in a growth chamber at a $23 / 16^{\circ} \mathrm{C}$ diurnal temperature cycle with a $16 \mathrm{hr}$ photoperiod. Seven days after the seed was sown, fully emerged seedlings were inoculated at the crown with $1 \mathrm{ml}$ of a single inoculum per seedling. Inocula selected represented major genera from litter and root microbial communities of arid, drought-adapted intermountain conifer forests of the PNW: Morchella snyderi (recovered from an ascocarp growing in litter of an intermountain conifer forest) and three fungi recovered from the root microbiome of Pseudotsuga menziesii var. glauca: Phialocephala sp. 'BHIAR', a novel xerophilic isolate of Penicillium (Penicillium sp. nova 'WPT111A3'), and the xerophilic Penicillium goetzii.

Inocula were generated from pure, 4-week-old cultures cultivated on potato dextrose agar (PDA). Plates containing the non-sporulating, mature cultures of M. snyderi and Phialocephala were flooded with sterile distilled water (SDW) and scraped with a sterile scalpel to remove the mycelium. Mycelia were then processed in a blender until finely fragmented before suspending in SDW. Final solutions of M. snyderi and Phialocephala BH1AR inocula 
were brought to volume at $6.3 \times 10^{4}$ and $2.3 \times 10^{6}$ fragments per ml, respectively. Plates of the sporulating Penicillium species P. goetzii and WPT111A3 were flooded with SDW and spores were loosened by passing a sterile bent glass rod over the mycelium. Spore solutions were suspended in SDW and final inocula of $P$. goetzii and WPT111A3 were brought to volume at $9.8 \times 10^{6}$ and $2.1 \times 10^{7}$ cells per ml, respectively. The fifth treatment or control consisted of SDW only.

Seedlings were returned to the growth chamber following inoculation, and the temperature was reduced to a $19 / 16^{\circ} \mathrm{C}$ diurnal cycle. Four days after inoculation, growth chamber temperatures were reduced to a $5 / 5^{\circ} \mathrm{C}$ diurnal cycle, and photoperiod was reduced to a $10 \mathrm{hr}$ daylength. Plants were vernalized at this temperature and daylength for 8 weeks, at which time seedlings were removed from the growth chamber. During vernalization, seedlings were fertilized with 24-8-16 N-P-K at $300 \mathrm{mg} \mathrm{l}^{-1}$ nitrogen every 2 weeks. Observations were taken before 85 seedlings were transplanted.

Following vernalization, seedlings were potted into 31 pots containing $323 \mathrm{~g}$ of soilless potting mix per liter. Plants were placed in a greenhouse at $21 / 15^{\circ} \mathrm{C}$ with a $16 \mathrm{hr}$ photoperiod. The plants were allowed to stabilize for $5 \mathrm{~d}$, at which time half of the seedlings in each forest fungal treatment were inoculated with a conidial suspension of the agricultural pathogen Fusarium culmorum at a concentration of $2.9 \times 10^{6}$ cells per ml. Ten $\mathrm{ml}$ of this Fusarium inoculum were applied to the crown of each seedling; each seedling within the pathogen-free group received $10 \mathrm{ml}$ of SDW. Plants were then given either sufficient (D-) or deficit moisture (D+) until harvest. Half the plants within each moisture treatment were then either inoculated with the root rot pathogen F. culmorum (FUS+) or not (FUS-). In order to accommodate the irrigation system design, the treatment $\mathrm{x}$ moisture $\mathrm{x}$ pathogen factorial was arranged in a split block design in three blocks with one half of each block receiving deficit moisture while the other half received sufficient moisture. Plants were randomly arranged within the blocks. Sufficient moisture was determined to be approximately $30 \%$ container capacity per irrigation event with deficit moisture determined to be $15 \%$ container capacity. Container capacity was determined to be 1.41 using the method described by Holstead (1983). All plants received 1.41 of 20-20-20 N-P-K fertilizer at of $200 \mathrm{mg} \mathrm{l}^{-1}$ nitrogen every 2 weeks. Each treatment $\mathrm{x}$ moisture $\mathrm{x}$ pathogen factorial contained 21 replicates giving a total of 420 plants.

Disease expression from pathogen infection was monitored over the course of the study. Colonization by treatment inocula was not assessed due to the difficulty of obtaining consistent reisolation in agaro. After 15 weeks, 
all plants were harvested. First, all seed heads were removed and counted. Seed heads were dried at $50{ }^{\circ} \mathrm{C}$ until they shattered and weighed on an analytical balance to determine yield. Tillers were also counted. Vegetative biomass was then severed from the roots at the crown. Above-ground biomass was dried at $50{ }^{\circ} \mathrm{C}$ until dry and weighed for vegetative yield. Root balls were removed from the pots, split in half and dried at $80{ }^{\circ} \mathrm{C}$ until all moisture was removed. A relative below-ground biomass was determined by weighing the entire root ball.

Fusarium culmorum and wheat- effects of a forest litter community

To determine the effectiveness of a conifer forest litter microbial community for suppression of the common wheat pathogen Fusarium culmorum, litter was collected from a pine forest understory in early spring (Idler's Rest Nature Reserve, Nature Conservancy, Moscow, ID, USA). Overstory vegetation was dominated by Pinus ponderosa with some Pseudotsuga menziesii var. glauca. Understory shrubs included oceanspray (Holodiscus discolor) and snowberry (Symphoricarpos albus). From this pine litter, 5 litter treatments were devised.

Half of the litter was autoclaved at $120^{\circ} \mathrm{C}$ for $45 \mathrm{~min}$ to produce an 'autoclaved litter' treatment and the other half was stored at cool temperatures $\left(\sim 2^{\circ} \mathrm{C}\right)$ until needed as the 'live litter' treatment. Four subsamples of each litter treatment were placed in 3.81 storage bags. The live litter subsamples were moist-incubated at $22^{\circ} \mathrm{C}$ for 3 weeks to enhance sporulation of fungi in the litter. The autoclaved litter subsamples were stored at $2^{\circ} \mathrm{C}$ until needed. After 3 weeks, the live litter subsamples were flushed with approximately $300 \mathrm{ml}$ of SDW, thoroughly shaken to loosen spores and microbial cells, and briefly flushed a second time. This mixed spore solution was filtered through four layers of cheese cloth to remove larger soil particles and plant debris and brought to a total volume of 1.51 with SDW to generate a "live litter wash" treatment. An 'autoclaved litter wash' treatment was produced in the same manner as 'live litter wash' from the autoclaved litter subsamples before being autoclaved at $120^{\circ} \mathrm{C}$ for $20 \mathrm{~min}$. The fifth treatment was a SDW control.

Seeds of wheat line 306 UI-SRG were sown in 10031 pots containing soilless potting mix. Twenty pots were mulched with autoclaved litter approximately $3 \mathrm{~cm}$ thick. Another 20 pots were likewise mulched with live litter. Following seedling emergence, seedlings in the remaining 60 non-mulched pots were inoculated at the crown with $10 \mathrm{ml}$ of one of the remaining three treatments ( 20 pots per treatment): live litter wash, autoclaved litter wash, 
and the SDW control. After 10 days, 10 plants from each of the 5 litter treatments were inoculated at the crown with $10 \mathrm{ml}$ of Fusarium culmorum suspension as previously described. The other 10 plants of each litter treatment received $10 \mathrm{ml}$ of SDW in place of Fusarium. Plants were grown for 9 weeks at a $25 / 19^{\circ} \mathrm{C}$ diurnal temperature cycle and $16 \mathrm{hr}$ photoperiod. Plants were not vernalized and were harvested for vegetative biomass only.

Plants were harvested for above-ground biomass by severing vegetative growth from the root at the crown. Above-ground tissues were dried in a drying oven at $70^{\circ} \mathrm{C}$ for $72 \mathrm{hrs}$ and then weighed on an analytical balance for dry biomass. Final plant survival was also determined.

Vernalization of wheat - effects of single fungal species

In the first experiment, wheat seedlings treated with fungal inoculants were found to stimulate root development during vernalization prior to inoculation with Fusarium culmorum, so another experiment was conducted using single species inoculum to confirm these effects during vernalization. Seeds of wheat line 306 UI-SRG were sown in $2 \mathrm{~cm}^{3} 80$-cell trays nested in seed flats. Seedlings were sprouted in a growth chamber at a $23 / 16^{\circ} \mathrm{C}$ diurnal temperature cycle with a $16 \mathrm{hr}$ photoperiod. Seven days after the seed was sown, fully emerged seedlings were inoculated at the crown with each seedling receiving $1 \mathrm{ml}$ of a single inoculum. Four fungal inocula were generated as described above, including Morchella snyderi, Phialocephala BH1AR, Penicillium WPT111A3. In this experiment, however, Penicillium goetzii was replaced as a treatment by an isolate of Phialocephala (BH1A) recovered from foliage of Pseudotsuga menziesii var. glauca to compare effects of foliar and root isolates of the same taxon. SDW was applied as a control. Eight trays were inoculated for each treatment. Following inoculation, 4 trays of each treatment were placed in a randomized block design in a greenhouse with a 9 hr photoperiod and a $25 / 19^{\circ} \mathrm{C}$ diurnal benchtop temperature cycle. The other 4 trays per treatment were returned to the growth chamber with a slightly reduced diurnal temperature cycle of $19 / 16^{\circ} \mathrm{C}$ and arranged in a randomized block design. Four days after inoculation, growth chamber temperatures were reduced to a $5 / 5^{\circ} \mathrm{C}$ diurnal cycle and photoperiod was reduced to a $9 \mathrm{hr}$ daylength. Seedlings at both benchtop and vernalization temperatures were fertilized every 2 weeks with 24-8-16 N-P-K at $300 \mathrm{mg} \mathrm{l}^{-1}$ nitrogen until harvest. Seedlings in the warm greenhouse were harvested 4 weeks following inoculation to prevent stress and senescence from the small plug size. Seedlings in the growth chamber 
were vernalized for 12 weeks before harvesting.

All seedlings were harvested by removing them from the trays, thoroughly washing roots to remove soil and debris, and severing above-ground biomass from root biomass at the crown. Root and above-ground tissues were dried in a drying oven at $70^{\circ} \mathrm{C}$ for $48 \mathrm{hrs}$ and then weighed on an analytical balance for dry biomass.

Statistical Analyses

Analysis of variance (ANOVA) and split-plot analyses were used to analyze factorial and main effects of treatments on yield, biomass, tiller, and head production of mature plants exposed to drought and Fusarium culmorum infection. Differences between means for the effects of treatment, irrigation, pathogen and factorial interactions were determined for least-squares (LS) mean comparisons at the 5\% level. LS mean comparisons were also used to analyze for treatment effects within three-factor interactions.

Above-ground vegetative biomass for plants in the litter experiment was analyzed for a complete randomized design. Mean biomass for the main effects of treatment was determined for both Fusarium-infected and Fusarium-free plants by ANOVA in SAS (SAS Inst., Inc., 2007). Severity of Fusarium infection was determined by mortality and survival as binomial data ( $1=$ alive, $0=$ dead). Total survival was analyzed by the Pearson chi-squared contingency test in R (Development Core Team, 2013).

Mean biomass for vegetative development of vernalized and non-vernalized seedlings was analyzed by ANOVA for a randomized complete block design for the main effects of treatment. Differences between means were determined by least-squares (LS) mean comparisons and Fisher's least significant difference (LSD) at the 5\% level.

Normality of all data was determined by residual and normality plots and univariate procedures. Normal, ANOVA, and factorial analyses were conducted using either UNIVARIATE, GLM and MIXED procedures using the statistical package SAS (SAS Inst., Inc., 2007).

\section{Results}


Effects of single forest fungi

Fusarium culmorum produced symptoms of infection in the crowns of winter wheat plants $14 \mathrm{~d}$ after inoculation in greenhouse studies. Within 6 weeks, all plants that received F. culmorum inoculum showed symptoms of infection in the crown, whereas every plant not challenged with the pathogen showed no signs of disease. Disease expression was limited to only those plants that received F. culmorum inoculum. Inoculation with F. culmorum (FUS+) explained $63.8 \%$ of variation in yield within the highly significant factorial model $\left(\mathrm{P}>0.0001 ; \mathrm{r}^{2}=0.773\right.$, Table 1$)$. Although moisture level (D+ plants were subjected to deficit moisture; D- plants received sufficient moisture) explained just $9.4 \%$ of the variation, FUS+/D+ plants did develop the most severe symptoms of disease, as expected, with the lowest yield (Table 2). In contrast, and also as expected, FUS-/D- plants exhibited the highest growth and yield in the absence of the biotic and abiotic stressors. Comparisons of growth and other response variables were similar to yield (Table 2).

Although treatment with forest fungi explained only $1.1 \%$ of yield variation within the model, it was significant $(\mathrm{P}=0.0009$, Table 1$)$. Interestingly, despite the marginal significance of the three-way interaction $(\mathrm{P}=$ 0.0665, Table 1), effects of fungal treatments were best observed in the third level factorial interactions. Despite Fusarium infection, Penicillium WPT111A3 doubled the yield of FUS+/D+ wheat plants ( $\mathrm{P}=0.0188$, Fig. 1A). Plants inoculated with Penicillium WPT111A3 produced twice the number of tillers ( $\mathrm{P}=0.0244)$ and heads $(\mathrm{P}=0.0256)$ compared to controls likely resulting from reduced severity of disease in the crown of FUS+/D+ plants. Penicillium WPT111A3 also increased both above- and below-ground biomass, although not significantly. The other three forest fungi did not affect yield of FUS+/D+ (Fig. 1A).

Another contribution to the highly explanatory yield model occurred in the absence of both disease and drought (i.e., in FUS-/D- plants). Penicillium WPT111A3 and Penicillium goetzii significantly increased yield $32.6 \%$ and $18.7 \%$, respectively, compared to untreated control plants ( $<<0.0003$, Fig. 1D). Penicillium WPT111A3 also increased above-ground vegetative biomass of FUS-/D- plants by $8.5 \%(\mathrm{P}=0.0397)$ compared to controls. Morchella snyderi and Phialocephala BH1AR had no effect on growth and yield regardless of Fusarium presence or absence or moisture status in this experiment. 
Effects of the forest litter community

Live microbes in the forest pine litter community increased survival and above-ground vegetative biomass (Fig. 2) of plants that were also inoculated with pathogenic Fusarium culmorum. Fusarium-inoculated plants all showed some signs of disease after 4 weeks. Plants that were not challenged with the pathogen showed no signs of disease. Both the live litter and live litter wash treatments resulted in better survival (70\% and $100 \%$, respectively) than the control (40\% survival). The live litter wash more than doubled survival compared to the Fusarium-infected control $\left(\chi^{2}=5.95, \mathrm{P}=0.015\right)$. Autoclaving must have eliminated those microbes that were responsible for improved survival as the autoclaved litter and autoclaved litter wash treatments did not improve survival (30\% and $20 \%$, respectively). Above-ground vegetative biomass was $65 \%$ greater $(\mathrm{P}<0.0001)$ for plants in the live litter wash compared to the control and 67\% greater $(\mathrm{P}<0.0001)$ for plants mulched with the live litter (Fig. 2). Autoclaved litter also increased biomass above Fusarium-infected controls ( $\mathrm{P}=0.0003)$, although to a lesser extent (55\%; Fig. 2).

It is important to note that these community-microbe treatments had no effect in the absence of the pathogen. Fusarium-free plants had 100\% survival and biomass differences among treatments were not observed (P $=0.5222)$. Mean biomass of Fusarium-free plants (37.4 g) was more than double that of Fusarium-infected plants $(17.1 \mathrm{~g})$.

Wheat vernalization and effects of single fungi

Each of the four individual forest fungi tested significantly stimulated root proliferation and development in vernalized wheat seedlings $(\mathrm{P}<0.0001$, Fig. 3A). Although inoculum colonization was not assessed given the difficulty of consistent reisolation microscopy indicated that inoculants could successfully colonize root tissues (Fig. 4). Three of the four fungi also significantly increased above-ground biomass during vernalization ( $\mathrm{P}<0.0001$, Fig. 3B). Although Morchella snyderi induced the greatest biomass production, significantly increasing root biomass by $19.9 \%$ and above-ground biomass by $14.7 \%$ compared to untreated controls $(\mathrm{P}<0.0001$, Fig. 3A and B).

Phialocephala spp. from the foliar and root microbiomes of Pseudotsuga menziesii var. glauca promoted shoot development by $9.8 \%(\mathrm{P}=0.0005)$ and $7.9 \%(\mathrm{P}=0.0036)$, respectively, and root development by as much as $17.4 \%$ $(\mathrm{P}=0.0002)$ and $18 \%(\mathrm{P}<0.0001)$, respectively, compared to untreated controls. Penicillium WPT111A3, the fungus 
that doubled yield in drought-stressed, Fusarium-infected wheat, stimulated a $12.3 \%$ increase in root biomass $(\mathrm{P}=0.0061)$ but failed to significantly increase above-ground biomass compared to the controls.

By contrast, non-vernalized seedlings grown at $25^{\circ} \mathrm{C}$ were, for the most part, not significantly affected by the addition of individual forest fungi (Fig. 3C and D). However, the foliar isolate of Phialocephala sp. increased above-ground biomass by $15.7 \%(\mathrm{P}<0.0217$, Fig. 3D).

\section{Discussion}

Our main finding (i.e., novel symbiosis between an introduced, agricultural crop (wheat) and fungi indigenous to Pacific Northwest forest) raises interesting questions. The scattered, disease-suppressive soils of the region could possibly be those soils that still harbor remnants of the native forest microbiome. Disease-suppressive soils could perhaps also be deliberately generated by addition of live forest litter or individual forest fungi. It is not known whether novel symbiosis is a possibility in other regions where wheat was introduced, but this study raises that question.

Despite moisture deficit conditions that favored severe Fusarium crown rot infection, a novel symbiosis between a forest rhizosphere Penicillium sp. 'WPT111A3' and the exotic agriculture host winter wheat mitigated yield losses in host plants exposed to the common soil-borne pathogen, Fusarium culmorum. Beneficial symbiotic behavior is sometimes expected in the presence of stress (Rodriguez and Redman, 2008), and in our first experiment, both abiotic (moisture deficit) and biotic stresses (F. culmorum) were present. However, in our second experiment without the abiotic stress of drought, we again saw a less defined novel symbiosis as damage due to $F$. culmorum was reduced by a pine litter community. The indigenous microbial community in live pine litter and live litter wash suppressed the disease effectively enough to double plant survival compared to plants that lacked association with the community, supporting Smith's (1967) and Schisler and Linderman's (1984) findings that forest soil and litter microbiomes may be active against pathogenic species of Fusarium.

Both Smith (1967) and Schisler and Linderman (1984) proposed the exclusion of Fusarium spp. from forest soils by indigenous soil microbes. In our experiments, F. culmorum was not excluded nor was incidence of the disease reduced across the experiment as all plants exposed to the pathogen became infected. Although we only 
quantified disease incidence and not the amount of the pathogen present in these studies, the nature of disease expression, reduced yield and plant mortality, allowed us to determine the disease suppressive abilities of both forest microbial communities and single forest microbes in terms of reduced disease severity and expression. Moreover, not all disease suppression in soils reduces the incidence of the pathogen in the soil. For example, in a recent study, Rabiey et al. (2015) found no reductions in absolute amounts of Fusarium crown rot DNA over time in Piriformospora indica-inoculated wheat plants although disease expression was significantly reduced by the presence of the symbiont, indicating that exclusion is not the sole mode of action in suppressive soils. Diseasesuppressive microbes can induce host resistance or reduce the ability of the pathogen to infect or severely damage the host (Weller et al., 2002). The abundance of microbes in the litter and rhizosphere communities of interior PNW forests and woodlands representing fungi capable of improving physiological and nutritional status of host plants while conferring tolerance to abiotic stress may be key to the Fusarium-suppressive ability of these microbes and microbial communities.

Drought-stressed wheat plants are known to be more susceptible to F. culmorum infection, and the disease becomes more severe in times of drought (Cook, 1973). Genetic resistance to root rots such as F. culmorum is weak, and among hard red wheat varieties, indirect methods of selective breeding for drought tolerance or avoidance have been ineffective as a means of control (Cook, 2007). It is, thus, a finding with applied potential that Penicillium WPT111A3 appears to be most effective in mediating both drought and pathogen resistance in hard red winter wheat. The mechanism may involve the xerophilic tendencies of Penicillium WPT111A3 that are the subject of further research.

We found that both Penicillium WPT111A3 and Phialocephala BH1AR readily colonize the roots of winter wheat (Fig. 4). With respect to positive treatment effects during low-temperature vernalization, it is interesting that Penicillium and DSE species, including Phialocephala, are frequently associated with cold, high-elevation and arctic or boreal environments where they are thought to help their hosts survive (Frisvad et al., 2006; Newsham et al., 2009; Rinu et al., 2012). Phialocephala and related DSE fungi have been frequently associated with increased nitrogen availability in plants and show greater symbiotic affinity with plants where organic nitrogen is available (Newsham, 2011). Some Penicillium spp. may also be capable of nitrogen mineralization (Allison et al., 2009). Likewise, some species of both DSE fungi and Penicillium are capable of solubilizing phosphate and releasing it for 
plant use (Kucey, 1987; Whitelaw, 2000; Mandyam and Jumpponen, 2005; Vyas et al., 2007). Since a number of these fungi are also capable of functioning at low temperatures (Newsham et al., 2009; Rinu et al., 2012), species from the interior PNW, where winters may be dry and cold, may facilitate uptake and assimilation of nutrients in plants at low temperatures, thereby facilitating continuous root development even during winter (i.e., vernalization) temperatures. With the exception of above-ground biomass in vernalized plants treated with Penicillium WPT111A3, differences in above- and below-ground biomass were lost at maturity. Artificial limitations imposed on natural above- and below-ground development through restricted pot volumes possibly resulted in equalization of treatments over time. However, under field conditions roots developing during the winter vernalization period would not be disturbed and would have fewer limitations on root development than those seen in the greenhouse. If such root development is possible in the over-wintering winter annual in field settings as well as imitative greenhouse experiments, it would likely produce stronger plants capable of better yields and greater disease tolerance. In some dryland wheat regions like the inland PNW, early development from stronger, larger root systems may allow the plant to tolerate the driest part of the year and F. culmorum (Cook 1973).

In native forest soils across the semi-arid interior PNW, Penicillium spp. dominate the top $8 \mathrm{~cm}$ of soil (Bollen and Wright, 1961) where crown rot pathogens, such as F. culmorum, would be expected to be most active. Phialocephala spp. are also among the most common root symbionts of native plant communities in these forest soils (Trowbridge and Jumpponen 2004; Ridout and Newcombe, unpublished). These fungi not only formed physical associations with a novel host (Fig. 4), wheat, but also suppressed the disease severity of a common pathogen and symbiotically mitigated vernalization stress in the exotic winter annual. Of 2500 isolates of Penicillium and 1800 isolates of DSE recovered from native plant communities in the intermountain PNW (Ridout and Newcombe, unpublished), we tested only two from each group; all four had significant effects on winter wheat development. Given the even stronger effects of the pine litter microbiome in mediating tolerance to $F$. culmorum, it is possible that many other indigenous forest microbes benefit wheat and perhaps other regional crops via novel symbioses and suppression of soil-borne disease and pathogens.

\section{Acknowledgements}


The authors would like to thank Jos Houbraken of CBS-KNAW Fungal Biodiversity Centre for sequencing and identification of Penicillium spp. used in this study and Posy Busby for sequencing Phialocephala spp. Kerry O'Donnell of USDA ARS NCAUR made the identification of Morchella snyderi. Timothy Paulitz of the USDA ARS Pullman contributed a Fusarium culmorum culture. Bill Price provided statistical advice. Funding for this project came from the National Science Foundation Center of Advanced Forest Systems award \#11P-0968821.

\section{References}

Ait Barka, E., Nowak, J., Clément, C. 2006. Enhancement of chilling resistance of inoculated grapevine plantlets with a plant growth-promoting Rhizobacterium, Burkholderia phytofirmans strain PsJN. Appl. Environ. Microbiol. 72, 7246-7252. doi: 10.1128/aem.01047-06.

Alabouvette, C., Rouxel, F., Louvet, J. 1979. Characteristics of Fusarium wilt-suppressive soils and prospects for their utilization in biological control. In: B. Shippers and W. Gams, (eds.) Soil borne plant pathogens. Academic Press, New-York, 165-182.

Allison, S. D., LeBauer, D. S., Ofrecio, M. R., Reyes, R., Ta, A. M., Tran, T. M. 2009. Low levels of nitrogen addition stimulate decomposition by boreal forest fungi. Soil Biol. Biochem. 41, 293-302.

Baynes, M., Newcombe, G., Dixon, L., Castlebury, L., O’Donnel,1 K. 2012. A novel plant-fungal mutualism associated with fire. Fungal Biol. 116, 133-144.

Black, A.E., Strand, E., Wright, R.G., Scott, J.M., Morgan, P., Watson, C. 1998. Land use history at multiple scales: implications for conservation planning. Landscape and Urban Planning 43, 49-63.

Bollen, W., Wright, E. 1961. Microbes and nitrates in soils from virgin and young-growth forests. Can. J. Microbiol. 7, 785-792.

Burke, D. 1954. Pathogenicity of Fusarium-solani f phaseoli in different soils. Phytopathology 44, 483-483.

Burke, D. 1965. Fusarium root rot of beans and behavior of the pathogen in different soils. Phytopathology 55, 122121. 
Cook, R., Papendick, R. 1972. Influence of water potential of soils and plants on root disease. Annu. Rev. Phytopathol. 10, 349-374.

Cook, R.J. 1973. Influence of low plant and soil water potentials on diseases caused by soilborne fungi. Phytopathology 63, 451-457.

Cook, R.J. 1980. Fusarium foot rot of wheat and its control in the Pacific Northwest. Plant Dis. 64, 1061-1066.

Cook, R.J. 1981. The influence of rotation crops on take-all decline phenomenon. Phytopathology 71, 89-81.

Cook, R.J. 2007. Tell me again what it is that you do. Annu. Rev. Phytopathol. 45, 1-23.

de Bary, A. 1879. Die Erscheinung der Symbiose. Verlag von Karl J. Trubner, Strasbourg, Germany.

Fierer, N., Ladau, J., Clemente, J.C., Leff, J.W., Owens, S.M., Pollard, K.S., Knight, R., Gilbert, J.A., McCulley, R.L. 2013. Reconstructing the microbial diversity and function of pre-agricultural tallgrass prairie soils in the United States. Science 342, 621-624.

Frisvad, J.C., Larsen, T.O., Dalsgaard, P.W., Seifert, K.A., Louis-Seize, G., Lyhne, E.K., Jarvis, B.B., Fettinger, J.C., Overy, D.P. 2006. Four psychrotolerant species with high chemical diversity consistently producing cycloaspeptide A, Penicillium jamesonlandense sp. nov., Penicillium ribium sp. nov., Penicillium soppii and Penicillium lanosum. Intern. J. Syst. Evol. Microbiol. 56, 1427-1437.

Gaudet, D., Chen, T. 1987. Effects of hardening and plant age on development of resistance to cottony snow mold (Coprinus psychromorbidus) in winter wheat under controlled conditions. Can. J. Bot. 65, 1152-1156.

Holstead, C. 1983. Good health, long life to the pot plant. Grower Talks 47, 60-63.

Houbraken, J., Frisvad, J.C., Seifert, K., Overy, D.P., Tuthill, D., Valdez, J., Samson, R. 2012. New penicillinproducing Penicillium species and an overview of section Chrysogena. Persoonia: Molecular Phyl. Evol. Fungi 29, 78-100.

Hubbard, M., Germida, J., Vujanovic, V. 2014. Fungal endophytes enhance wheat heat and drought tolerance in terms of grain yield and second-generation seed viability. J. Appl. Microbiol. 116, 109-122. 
Kershaw, L. J., MacKinnon, A., Pojar, J. 1998. Plants of the Rocky Mountains. Lone Pine Publishing, Auburn WA.

Kim, D.S., Cook, R.J., Weller, D.M. (1997) Bacillus sp. L324-92 for biological control of three root diseases of wheat grown with reduced tillage. Phytopathology 87, 551-558.

Kinkel, L.L., Bakker, M.G., Schlatter, D.C. 2011. A coevolutionary framework for managing disease-suppressive soils. Annu. Rev. Phytopathol. 49, 47-67.

Kloepper, J.W., Leong, J., Teintze, M., Schroth, M.N. 1980. Pseudomonas siderophores: a mechanism explaining disease-suppressive soils. Current Microbiol. 4, 317-320.

Knapp, D.G., Pintye, A., Kovács, G.M. 2012. The dark side is not fastidious-dark septate endophytic fungi of native and invasive plants of semiarid sandy areas. PLOS one 7, e32570.

Kucey, R. 1987. Increased phosphorus uptake by wheat and field beans inoculated with a phosphorus-solubilizing Penicillium bilaji strain and with vesicular-arbuscular mycorrhizal fungi. Appl. Environ. Microbiol. 53, 2699-2703.

Larkin, R.P., Hopkins, D.L., Martin, F.N. 1996. Suppression of Fusarium wilt of watermelon by non-pathogenic Fusarium oxysporum and other microorganisms recovered from a disease-suppressive soil. Phytopathology $86,812-819$.

Lin, Y., Cook, R. 1979. Suppression of Fusarium roseum ‘Avenaceum’by soil microorganisms. Phytopathology 69, 384-388.

Liu, S.D., Baker, R. 1980. Mechanism of biological control in soil suppressive to Rhizoctonia solani. Phytopathology 70, 404-412.

Mandyam, K., Jumpponen, A. 2005. Seeking the elusive function of the root-colonising dark septate endophytic fungi. Studies in Mycology 53, 173-189.

Mazzola, M. 1999. Transformation of soil microbial community structure and Rhizoctonia-suppressive potential in response to apple roots. Phytopathology 89, 920-927. 
Newsham, K.K., Upson, R., Read, D. 2009. Mycorrhizas and dark septate root endophytes in polar regions. Fungal Ecol. 2, 10-20.

Newsham, K.K. 2011. A meta-analysis of plant responses to dark septate root endophytes. New Phytol. 190, 783793.

Papendick, R., Cook, R. 1974. Plant water stress and development of Fusarium foot rot in wheat subjected to different cultural practices. Phytopathology 64, 358-363.

Paulitz, T.C. 2006. Low input no-till cereal production in the Pacific Northwest of the U.S.: the challenges of root diseases. Europ. J. Plant Path. 115, 271-281.

Peters, R., Sturz, A., Carter, M., Sanderson, J. 2003. Developing disease-suppressive soils through crop rotation and tillage management practices. Soil Tillage Res. 72, 181-192.

Pitt, J.I. 1973. An appraisal of identification methods for Penicillium species: novel taxonomic criteria based on temperature and water relations. Mycologia 65, 1135-1157.

R Development Core Team. 2013. R: A language and environment for statistical computing. R Foundation for Statistical Computing, Vienna, Austria. ISBN 3-900051-07-0, URL http://www.R-project.org.

Raaijmakers, J.M., Weller, D.M., Thomashow, L.S. 1997. Frequency of antibiotic-producing Pseudomonas spp. in natural environments. Appl. Environ. Microbiol. 63, 881-887.

Rabiey, M., Ullah, I., Shaw, M.W. 2015. The endophytic fungus Piriformospora indica protects wheat from fusarium crown rot disease in simulated UK autumn conditions. Plant Path.. doi: 10.1111/ppa.12335.

Rodriguez, R., Redman, R. 2008, More than 400 million years of evolution and some plants still can't make it on their own: plant stress tolerance via fungal symbiosis. J. Exp. Bot. 59, 1109-1114.

Richardson, D.M., Allsopp, N., d'Antonio, C.M., Milton, S.J., Rejmanek, M. 2000. Plant invasions-the role of mutualisms. Biol. Revs. 75, 65-93.

Rinu, K., Pandey, A., Palni, L.M.S. 2012. Utilization of psychrotolerant phosphate solubilizing fungi under low 
temperature conditions of the mountain ecosystem. In: T. Satyanarayana, B. Narain Johri, A. Prakash, (eds.) Microorganisms in Sustainable Agriculture and Biotechnology. Springer, The Netherlands, 77-90.

SAS Inst. Inc. 2007. SAS 9.2 for Windows, Statistical Analysis Systems Institute, Inc., Cary, NC.

Scher, F.M., Baker, R. 1980. Mechanism of biological control in a Fusarium-suppressive soil. Phytopathology 70, 412-417.

Schisler, D.A., Linderman, R. 1984. Evidence for the involvement of the soil microbiota in the exclusion of Fusarium from coniferous forest soils. Can. J. Microbiol. 30, 142-150.

Shipton, P., Cook, R., Sitton, J. 1973. Occurrence and transfer of a biological factor in soil that suppresses take-all of wheat in eastern Washington. Phytopathology 63, 511-517.

Smiley, R.W., Patterson, L.M. 1996. Pathogenic fungi associated with Fusarium foot rot of winter wheat in the semiarid Pacific Northwest. Plant Dis. 80, 944-949.

Smith, R. 1967. Decline of Fusarium oxysporum in roots of Pinus lambertiana seedlings transplanted into forest soils. Phytopathology 57, 1265.

Trowbridge, J., Jumpponen, A. 2004. Fungal colonization of shrub willow roots at the forefront of a receding glacier. Mycorrhiza 14, 283-293.

Turner, M., Kuhlmann, E. 2014. Trees and Shrubs of the Pacific Northwest: Timber Press Field Guide. Timber Press, Portland OR.

Vyas, P., Rahi, P., Chauhan, A., Gulati, A. 2007. Phosphate solubilization potential and stress tolerance of Eupenicillium parvum from tea soil. Mycological Res. 111, 931-938.

Weller, D. 1983. Colonization of wheat roots by a fluorescent pseudomonad suppressive to take-all. Phytopathology $73,1548-1553$.

Weller, D., Cook, R. 1983. Suppression of take-all of wheat by seed treatments with fluorescent pseudomonads. Phytopathology 73, 463-469. 
Weller, D.M., Raaijmakers, J.M., Gardener, B.B.M., Thomashow, L.S. 2002. Microbial populations responsible for specific soil suppressiveness to plant pathogens 1. Annu. Rev. Phytopathol. 40, 309-348.

Whitelaw, M. A. 1999. Growth promotion of plants inoculated with phosphate-solubilizing fungi. Advances in Agronomy, 69, 99-151. 


\section{Figure Captions}

Fig. 1 Indigenous forest fungi increased the per plant yield in hard red wither wheat. (A) Penicillium sp. WPT111A3 more than doubled yield in FUS+/D+ stressed plants compared to controls. Two out of three forest fungi increased yield (but not significantly) in (B) FUS+/D- plants and (C) FUS-/D+ plants relative to controls. (D) Penicillium spp. also significantly increased yield of FUS-/D- compared to untreated controls. Different letters indicate significant differences $(\mathrm{P}<0.05)$. Error bars indicate standard error $(\alpha=0.05)$.

Fig. 2 Vegetative above-ground biomass of winter wheat plants infected with Fusarium culmorum was significantly greater when mulched with either live or autoclaved pine litter or when treated with live litter wash. Different letters indicate significant differences $(\mathrm{P}<0.05)$. Error bars indicate standard error $(\alpha=0.05)$.

Fig. 3 Seedlings inoculated with forest fungi had better overall growth under low temperature stress of vernalization compared to untreated controls. (A) All four fungal treatments significantly increased root biomass of seedlings grown for 12 weeks at $5^{\circ} \mathrm{C}$ when compared to the control, and (B) three significantly increased above-ground biomass compared to the control. (C) By contrast, there were no significant differences in root biomass after four weeks growth at $25^{\circ} \mathrm{C}$. (D) However, the foliar isolate of Phialocephala significantly increased above-ground biomass at $25^{\circ} \mathrm{C}$ compared to the untreated controls. Different letters indicate significant differences $(\mathrm{P}<0.05)$. Error bars indicate standard error $(\alpha=0.05)$.

Fig. 4 Phialocephala and Penicillium were both capable of forming physical associations with winter wheat by colonizing roots that led to novel symbioses. Light micrographs revealed internal colonization of cells and tissues. Left: Phialocephala internally colonizing a root hair of a wheat seedling. The arrow indicates a microsclerotium in the root hair. Right: Penicillium WPT colonizing root cells of a wheat seedling. Arrows indicate hyphae within cells. Scale bars are $20 \mu \mathrm{m}$. 

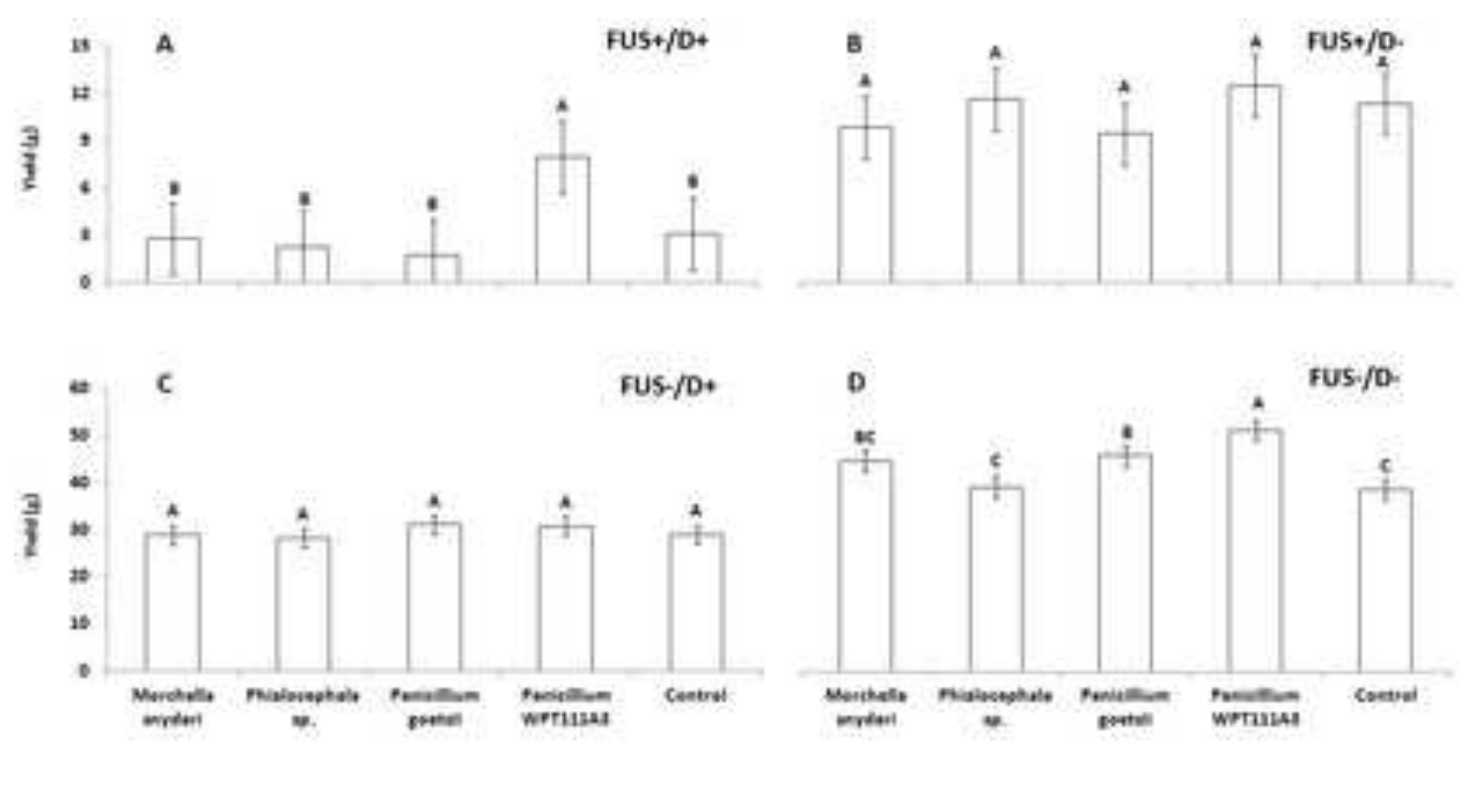

Figure 1

1

.

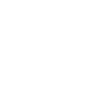

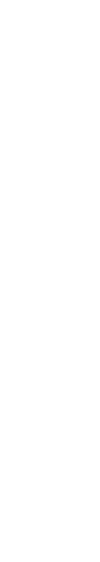

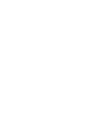




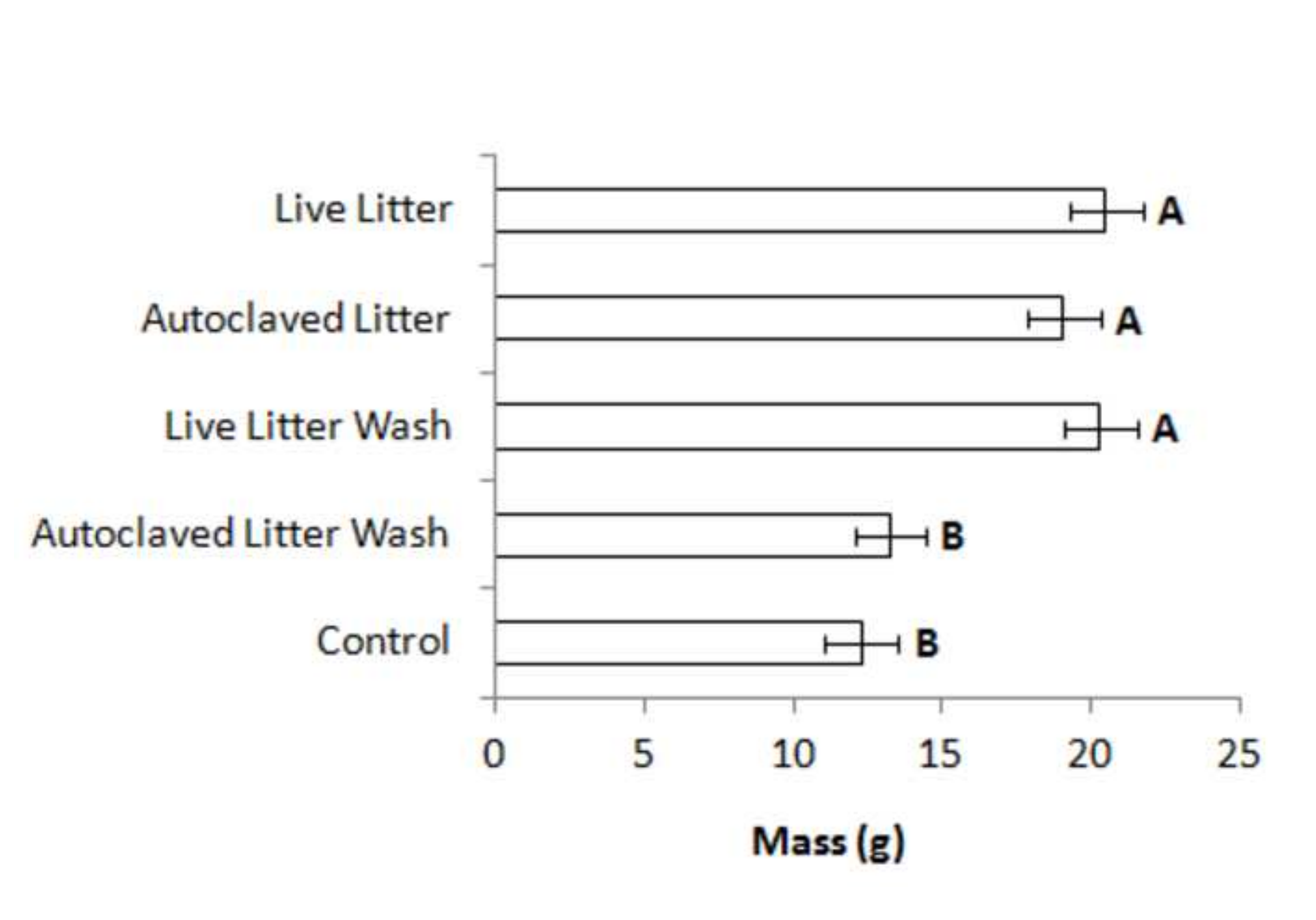

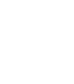




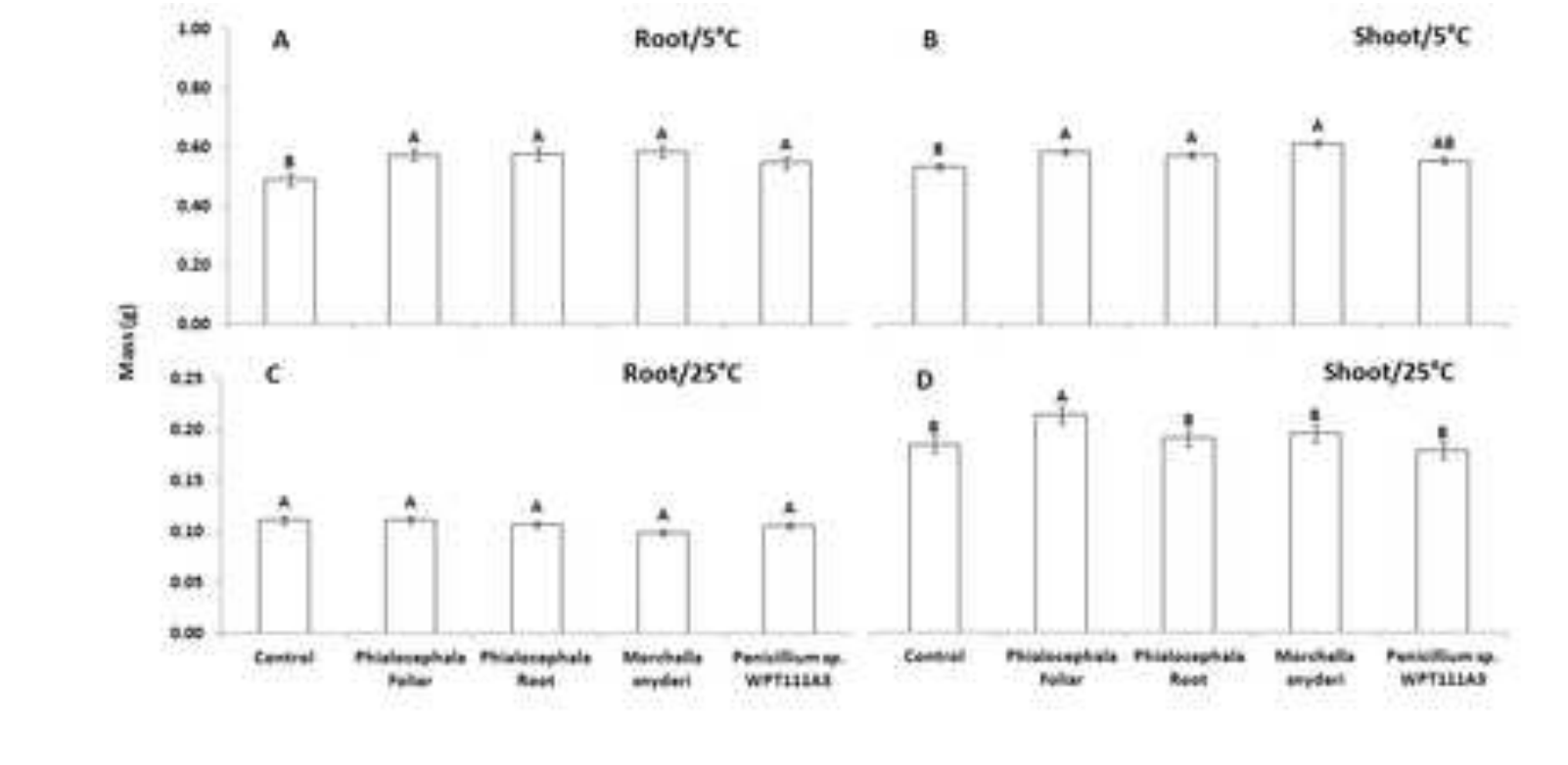

Figure 3 

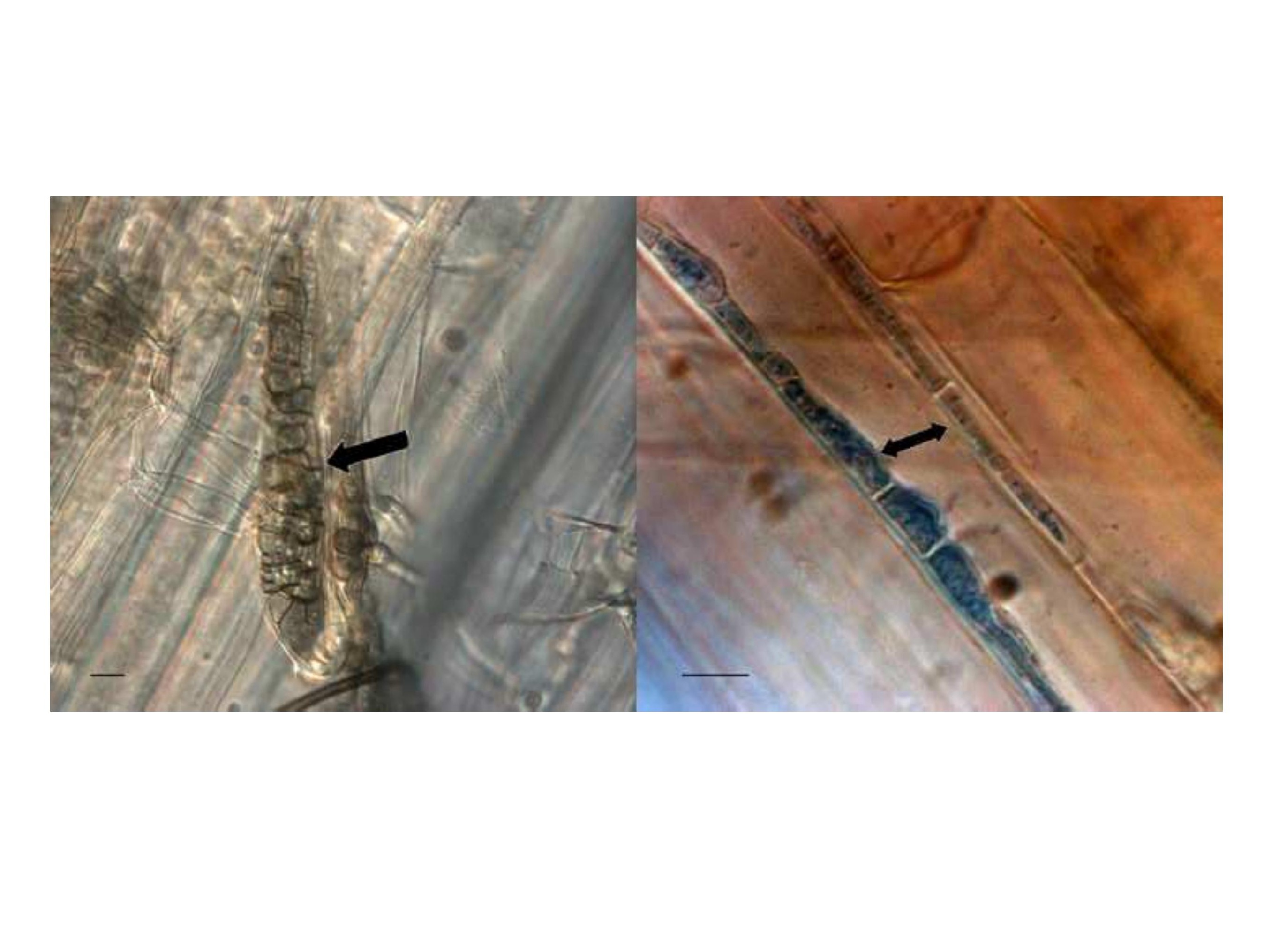
Table 1 Summary statistics for the main effects and interactions of the factorial model, including partitioning of the variance, F statistics, and probability values. For most variables measured, main effects were significant $(\mathrm{P}<0.05)$.

\begin{tabular}{|c|c|c|c|c|c|c|c|}
\hline Variable & Source & DF & Type III SS & Mean Square & $\mathrm{R}^{2}$ & F-value & P-value \\
\hline \multirow[t]{8}{*}{ Yield } & Treatment $\left({ }^{\mathrm{a}} \mathrm{T}\right)$ & 4 & 1600.22 & 400.06 & 0.0110 & 4.77 & 0.0009 \\
\hline & Moisture deficit ( $\left.{ }^{b} D+/-\right)$ & 1 & 13612.11 & 13612.11 & 0.0937 & 162.2 & $<.0001$ \\
\hline & Fusarium ( $\left.{ }^{\mathrm{C}} \mathrm{FUS}+/-\right)$ & 1 & 92598.92 & 92598.92 & 0.6371 & 1103.42 & $<.0001$ \\
\hline & $(\mathrm{D}+/-)^{*}(\mathrm{FUS}+/-)$ & 1 & 1625.36 & 1625.36 & 0.0112 & 19.37 & $<.0001$ \\
\hline & $(T) *(D+/-)$ & 4 & 152.45 & 38.11 & 0.0010 & 0.45 & 0.7694 \\
\hline & $(T) *(F U S+/-)$ & 4 & 632.11 & 158.03 & 0.0043 & 1.88 & 0.1126 \\
\hline & $(T) *(D+/-) *(F U S+/-)$ & 4 & 744.34 & 186.09 & 0.0051 & 2.22 & 0.0665 \\
\hline & Model & 19 & 112364.03 & 5913.90 & 0.7731 & 70.47 & $<.0001$ \\
\hline \multirow[t]{8}{*}{ Head } & Treatment $(\mathrm{T})$ & 4 & 207.37 & 51.84 & 0.0090 & 3.66 & 0.0061 \\
\hline & Moisture deficit (D +/-) & 1 & 3576.19 & 3576.19 & 0.1557 & 252.49 & $<.0001$ \\
\hline & Fusarium (FUS+/-) & 1 & 13224.60 & 13224.60 & 0.5757 & 933.68 & $<.0001$ \\
\hline & $(D+/-) *($ FUS $+/-)$ & 1 & 17.06 & 17.06 & 0.0007 & 1.20 & 0.2700 \\
\hline & $(T) *(D+/-)$ & 4 & 22.96 & 5.74 & 0.0010 & 0.41 & 0.8049 \\
\hline & $(\mathrm{T}) *(\mathrm{FUS}+/-)$ & 4 & 55.72 & 13.93 & 0.0024 & 0.98 & 0.4163 \\
\hline & $(T) *(D+/-) *(F U S+/-)$ & 4 & 60.96 & 15.24 & 0.0027 & 1.08 & 0.3680 \\
\hline & Model & 19 & 17405.14 & 916.06 & 0.7577 & 64.68 & $<.0001$ \\
\hline \multirow[t]{8}{*}{ Tiller } & Treatment $(\mathrm{T})$ & 4 & 285.38 & 71.34 & 0.0067 & 1.71 & 0.1461 \\
\hline & Moisture deficit (D +/-) & 1 & 12163.69 & 12163.69 & 0.2859 & 292.16 & $<.0001$ \\
\hline & Fusarium (FUS+/-) & 1 & 11992.96 & 11992.96 & 0.2819 & 288.06 & $<.0001$ \\
\hline & $(D+/-) *($ FUS $+/-)$ & 1 & 451.92 & 451.92 & 0.0106 & 10.85 & 0.0011 \\
\hline & $(T) *(D+/-)$ & 4 & 170.42 & 42.61 & 0.0040 & 1.02 & 0.3950 \\
\hline & $(\mathrm{T})^{*}(\mathrm{FUS}+/-)$ & 4 & 249.39 & 62.35 & 0.0059 & 1.5 & 0.2022 \\
\hline & $(T) *(D+/-) *(F U S+/-)$ & 4 & 432.82 & 108.21 & 0.0102 & 2.6 & 0.0359 \\
\hline & Model & 19 & 26226.65 & 1380.35 & 0.6164 & 33.15 & $<.0001$ \\
\hline \multirow[t]{8}{*}{ Shoot Biomass } & Treatment $(T)$ & 4 & 1735.05 & 433.76 & 0.0101 & 3.87 & 0.0043 \\
\hline & Moisture deficit (D +/-) & 1 & 100064.42 & 100064.42 & 0.5852 & 892.92 & $<.0001$ \\
\hline & Fusarium (FUS+/-) & 1 & 22871.90 & 22871.90 & 0.1338 & 204.1 & $<.0001$ \\
\hline & $(\mathrm{D}+/-) *(\mathrm{FUS}+/-)$ & 1 & 213.83 & 213.83 & 0.0013 & 1.91 & 0.1680 \\
\hline & $(T) *(D+/-)$ & 4 & 416.33 & 104.08 & 0.0024 & 0.93 & 0.4471 \\
\hline & $(\mathrm{T}) *(\mathrm{FUS}+/-)$ & 4 & 182.71 & 45.68 & 0.0011 & 0.41 & 0.8032 \\
\hline & $(T) *(D+/-) *(F U S+/-)$ & 4 & 123.18 & 30.80 & 0.0007 & 0.27 & 0.8942 \\
\hline & Model & 19 & 127505.95 & 6710.84 & 0.7457 & 59.88 & $<.0001$ \\
\hline \multirow[t]{8}{*}{ Root Biomass } & Treatment $(\mathrm{T})$ & 4 & 1549.17 & 387.29 & 0.0117 & 2.51 & 0.0412 \\
\hline & Moisture deficit (D +/-) & 1 & 29118.80 & 29118.80 & 0.2206 & 189.09 & $<.0001$ \\
\hline & Fusarium (FUS+/-) & 1 & 34798.16 & 34798.16 & 0.2637 & 225.97 & $<.0001$ \\
\hline & $(\mathrm{D}+/-) *(\mathrm{FUS}+/-)$ & 1 & 69.22 & 69.22 & 0.0005 & 0.45 & 0.5030 \\
\hline & $(T) *(D+/-)$ & 4 & 356.27 & 89.07 & 0.0027 & 0.58 & 0.6785 \\
\hline & $(\mathrm{T}) *(\mathrm{FUS}+/-)$ & 4 & 4259.61 & 1064.90 & 0.0323 & 6.92 & $<.0001$ \\
\hline & $(T) *(D+/-) *(F U S+/-)$ & 4 & 579.88 & 144.97 & 0.0044 & 0.94 & 0.4399 \\
\hline & Model & 19 & 72382.75 & 3809.62 & 0.5484 & 24.74 & $<.0001$ \\
\hline
\end{tabular}

${ }^{\mathrm{a}} \mathrm{T}=$ Treatment effect. ${ }^{\mathrm{b}} \mathrm{D}=$ moisture deficit effect, presence $(+) /$ absence $(-) .{ }^{\mathrm{c}} \mathrm{FUS}=$ Fusarium effect, presence (+) /absence (-). 
Table 2 The main effects of Fusarium infection (FUS+) and moisture deficit (D+) significantly reduced mean productivity of winter wheat plants constituting slightly over $75 \%\left(\mathrm{r}^{2}=0.77\right)$ of the variation in the model. The interactions of these main effects also reduced mean productivity as described by the five response variables.

\begin{tabular}{|c|c|c|c|c|c|c|c|}
\hline \multirow{2}{*}{$\begin{array}{l}\text { Fusarium } \\
\text { Infection }\end{array}$} & \multirow{2}{*}{$\begin{array}{l}\text { Moisture } \\
\text { Deficit }\end{array}$} & \multirow{2}{*}{$\begin{array}{c}\text { Survival } \\
(\%)\end{array}$} & Yield & Head \# & Tiller \# & Shoot Biomass & Root Biomass \\
\hline & & & \multicolumn{5}{|c|}{ (Meana \pm SEb) } \\
\hline FUS $(-)^{c}$ & - & 100 & $37.322 \pm 0.722$ & $17.0 \pm 0.2$ & $22.3 \pm 0.5$ & $89.79 \pm 0.99$ & $331.34 \pm 1.60$ \\
\hline FUS(+) & - & 85.6 & $7.324 \pm 0.722$ & $5.6 \pm 0.2$ & $11.5 \pm 0.5$ & $44.86 \pm 0.99$ & $312.83 \pm 1.60$ \\
\hline- & $D(-)^{d}$ & 99.5 & $28.047 \pm 0.722$ & $14.3 \pm 0.2$ & $22.3 \pm 0.5$ & $88.66 \pm 0.99$ & $330.57 \pm 1.60$ \\
\hline- & $D(+)$ & 85.9 & $16.599 \pm 0.722$ & $8.4 \pm 0.2$ & $11.5 \pm 0.5$ & $46.00 \pm 0.99$ & $313.60 \pm 1.60$ \\
\hline FUS(-) & $\mathrm{D}(-)$ & 100 & $45.028 \pm 1.021$ & $19.7 \pm 0.3$ & $26.7 \pm 0.6$ & $113.83 \pm 1.40$ & $339.43 \pm 2.26$ \\
\hline FUS(-) & $D(+)$ & 100 & $29.617 \pm 1.021$ & $14.2 \pm 0.3$ & $18.0 \pm 0.6$ & $65.75 \pm 1.40$ & $323.25 \pm 2.26$ \\
\hline FUS(+) & $D(-)$ & 99 & $11.066 \pm 1.021$ & $8.8 \pm 0.3$ & $17.9 \pm 0.6$ & $63.49 \pm 1.40$ & $321.72 \pm 2.26$ \\
\hline FUS(+) & $D(+)$ & 72.4 & $3.582 \pm 1.021$ & $2.5 \pm 0.3$ & $5.0 \pm 0.6$ & $26.24 \pm 1.40$ & $303.95 \pm 2.26$ \\
\hline
\end{tabular}

${ }^{\mathrm{a}}$ Average mass in grams per plant. ${ }^{\mathrm{b}} \mathrm{SE}=$ Standard Error $\alpha=0.05$. ${ }^{\mathrm{c}} \mathrm{FUS}=$ Fusarium infection, presence (+) /absence (-). ${ }^{\mathrm{d}} \mathrm{D}=\mathrm{moisture}$ deficit, presence (+) /absence (-). 